\title{
Radiotherapy Remains Underused in the Treatment of Soft-Tissue Sarcomas: Disparities in Practice Patterns in the United States
}

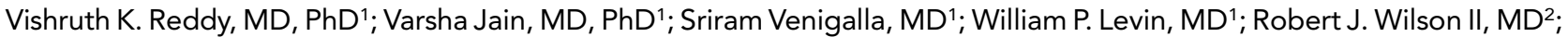 \\ Kristy L. Weber, MD²; Anusha Kalbasi, MD³; Ronnie A. Sebro, MD, PhD²,45,6; and Jacob E. Shabason, MD, MTR ${ }^{1}$
}

\begin{abstract}
Background: Practice patterns of radiation therapy (RT) use for softtissue sarcoma (STS) remain quite variable, despite clinical practice guidelines recommending the addition of RT to surgery for patients with high-grade STS, particularly for larger tumors. Using the National Cancer Database (NCDB), we assessed patterns of overall RT use, neoadjuvant versus adjuvant treatment, and specific RT modalities in this population. Patients and Methods: Patients aged $\geq 18$ years with stage II/III STS in 2004 through 2015 were identified from the NCDB. Patterns of care were assessed using multivariable logistic regression analysis. Results: Of 27,426 total patients, 11,654 (42\%) were treated with surgery alone versus 15,772 (58\%) with RT in addition to surgery, with no overall increase in RT use over the study period. Notable clinical predictors of receipt of RT included tumor size $(>5 \mathrm{~cm})$, grade III, and tumors arising in the extremities. Conversely, female sex, older age ( $\geq 70$ years), Black race, noncommercial insurance coverage, farther distance to treatment, and poor performance status were negative predictors of RT use. Of those receiving RT, $27 \%$ were treated with neoadjuvant RT and $73 \%$ with adjuvant RT. The proportion of those receiving neoadjuvant RT increased over time. Relevant factors associated with neoadjuvant RT included treatment at academic centers, larger tumor size, and extremity tumors. Of those who received RT with a modality specified as either intensity-modulated RT (IMRT) or 3D conformal RT (3DCRT), $61 \%$ were treated with IMRT and $39 \%$ with 3DCRT. The proportion of patients treated with IMRT increased over time. Relevant factors associated with IMRT use included treatment at academic centers, commercial insurance coverage, and larger and nonextremity tumors. Conclusions: Although use of neoadjuvant RT and IMRT has increased over time, a significant number of patients with STS are not receiving adjuvant or neoadjuvant RT. Our findings also note potential sociodemographic disparities and highlight the concern that not all patients with STS are being equally considered for RT.
\end{abstract}

J Natl Compr Canc Netw 2021;19(3):295-306 doi: $10.6004 /$ jnccn.2020.7625

\footnotetext{
${ }^{1}$ Department of Radiation Oncology, and ${ }^{2}$ Department of Orthopedic Surgery, Hospital of the University of Pennsylvania, Philadelphia, Pennsylvania; ${ }^{3}$ Department of Radiation Oncology, UCLA Medical Center, Los Angeles, California; ${ }^{4}$ Department of Radiology, Hospital of the University of Pennsylvania, Philadelphia, Pennsylvania; and ${ }^{5}$ Department of Genetics and ${ }^{6}$ Department of Biostatistics, Epidemiology and Bioinformatics, University of Pennsylvania, Philadelphia, Pennsylvania.
}

\section{Background}

Soft-tissue sarcomas (STS) constitute approximately $1 \%$ of all cancers diagnosed yearly in the United States and are a heterogeneous group of mesenchymal malignancies. ${ }^{1}$ Their management is best achieved with multidisciplinary care involving surgery, radiation oncology, medical oncology, radiology, and pathology. ${ }^{2}$ NCCN Clinical Practice Guidelines in Oncology (NCCN Guidelines) for STS recommend the addition of neoadjuvant or adjuvant radiation therapy (RT) to surgery for patients with high-grade STS, ${ }^{2}$ particularly for larger tumors, given that randomized data have shown improvement in local control with the addition of RT. ${ }^{3-5}$ In addition, studies have shown that neoadjuvant RT may offer select benefits for patients with extremity STS treated with RT, including smaller treatment volume and lower dose, which translate to a lower risk of late radiation-induced complications, such as edema, fibrosis, and joint stiffness. However, neoadjuvant RT is associated with a higher risk of acute wound complications compared with adjuvant RT. ${ }^{6}$ Moreover, recent data have noted potential benefits in the use of intensity-modulated RT (IMRT). ${ }^{7,8}$ Yet, despite the benefits of RT in the management of high-grade sarcomas, there appears to be significant heterogeneity in its use, in addition to concern among providers regarding its potential underuse. ${ }^{9-11}$ The aim of this study was to better understand the patterns of multidisciplinary care and to quantify variations in practice, perioperative timing, and modality with respect to RT use in the management of patients with stage II/III STS using the National Cancer Database (NCDB).

\section{Patients and Methods}

\section{Data Source}

The study population was identified from the NCDB, a national cancer registry jointly sponsored by the American College of Surgeons and the American Cancer Society

See JNCCN.org for supplemental online content. 
that draws on hospital registry data from $>1,500$ Commission on Cancer-accredited facilities in the United States. ${ }^{12,13}$ The dataset captures $>70 \%$ of incident cancers and comprises $>34$ million unique cancer cases. ${ }^{12,13}$ Data are collected prospectively from Commission on Canceraccredited program cancer registries with nationally standardized data-coding definitions.

\section{Study Population}

Inclusion criteria (see supplemental eFigure 1, available with this article at JNCCN.org) for the cohort consisted of patients aged $\geq 18$ years with high-grade (stage II or III), nonmetastatic, nonretroperitoneal STS treated with surgery with or without perioperative RT (not including brachytherapy) in 2004 through 2015. Patients who underwent amputation were excluded because RT would not be indicated. Patients with STS arising in the head, neck, extremities, thorax, trunk, abdomen, and pelvis and those with the following common adult STS histologies were included: undifferentiated or unclassified histology, undifferentiated pleomorphic sarcoma, liposarcoma, leiomyosarcoma, fibrosarcoma/myxofibrosarcoma, synovial sarcoma, angiosarcoma, and malignant peripheral nerve sheath tumor.

\section{Patient Cohorts and Variables}

Covariates examined included age; sex; race/ethnicity; facility area (classified as metropolitan, urban, or rural based on data published by the US Department of Agriculture Economic Research Service); insurance; education level (defined as percentage of population in patient's zip code without a high school degree, which is derived from the US Census data); income level (defined as median income in patient's zip code); facility geographic location; facility type (nonacademic or academic, with "academic" referring to academic/research programs including NCI-designated Comprehensive Cancer Centers); distance to treatment facility (calculated as distance between patient's zip code center and hospital street address); Charlson-Deyo comorbidity index score ${ }^{14}$; primary tumor site; tumor histology, grade, and size; receipt of chemotherapy; and year of diagnosis.

\section{Statistical Analysis}

Baseline characteristics of the study cohorts were compared using Pearson's chi-square tests. Covariates achieving a threshold significance of $P<.1$ in univariate analysis were included in the multivariable logistic regression model. A multivariable logistic regression model was constructed using all baseline covariates to assess the independent effect of each covariate on the odds of being treated with RT, receiving neoadjuvant versus adjuvant RT, or receiving IMRT versus 3D conformal RT (3DCRT). A 2-tailed $P$ value $<.05$ was considered statistically significant.
Statistical analyses were performed using Stata/SE, version 15.0 (StataCorp LLP).

\section{Results}

\section{Baseline Clinical Characteristics}

A total of 27,426 patients met the study inclusion criteria. Complete patient characteristics are shown in supplemental eTable 1. Notably, the median age of the patient cohort was 63 years (range, 18-90 years). Most patients were men $(54 \%)$, of non-Hispanic White race/ethnicity $(80 \%)$, and without significant comorbid illness $(81 \%)$. It was less common for patients to receive treatment at a nonacademic facility $(42 \%)$ and at a facility $>40$ miles from their residence $(26 \%)$. In terms of disease characteristics, most patients had tumors arising in the extremities (58\%), grade III disease (77\%), and tumor size $>5 \mathrm{~cm}(64 \%)$.

Overall, $58 \%$ of patients received RT. Of those with larger tumors $(>5 \mathrm{~cm}), 62 \%$ were treated with perioperative RT. Of those who received RT, most received RT adjuvantly $(73 \%)$ rather than neoadjuvantly $(27 \%)$. Of those who received RT with modality specified as IMRT or 3DCRT, more were treated with IMRT (61\%) than with 3DCRT (39\%) (supplemental eFigure 1).

\section{Factors Associated With Receipt of RT}

Use of RT did not increase between 2004 and 2015 (Figure 1). Multivariable analysis revealed that sociodemographic factors associated with omission of RT were Black race, female sex, older age, noncommercial insurance coverage, and farther distance from treatment site. Notable clinical factors associated with decreased RT use were nonextremity tumors, smaller tumors $(\leq 5 \mathrm{~cm})$, lower-grade tumors (grade II vs III), and higher comorbidity score (Table 1). When specifically evaluating patients with larger tumors $(>5 \mathrm{~cm}$ ) (supplemental eTable 2) or abdominal/pelvic tumors (supplemental eTable 3), we found that similar demographic and clinical factors were associated with RT use.

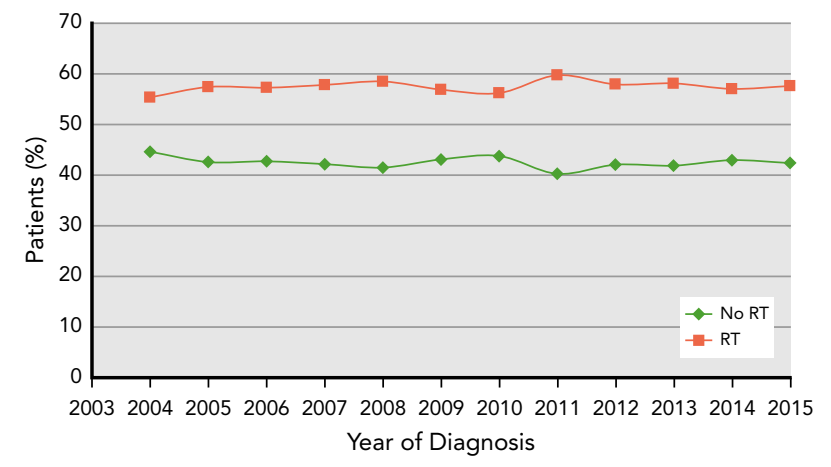

Figure 1. Trends in receipt of surgery alone or surgery in addition to perioperative RT.

Abbreviation: RT, radiation therapy. 


\begin{tabular}{|c|c|c|c|c|}
\hline \multirow[b]{2}{*}{ Factor } & \multicolumn{2}{|c|}{ Univariate Analysis } & \multicolumn{2}{|c|}{ Multivariate Analysis } \\
\hline & OR $(95 \% \mathrm{Cl})$ & $P$ Value & OR $(95 \% \mathrm{Cl})$ & $P$ Value \\
\hline \multicolumn{5}{|l|}{ Age } \\
\hline$<70 y$ & Ref & & Ref & \\
\hline$\geq 70 y$ & $0.85(0.81-0.90)$ & $<.001$ & $0.88(0.82-0.94)$ & $<.001$ \\
\hline Male & Ref & & Ref & \\
\hline Female & $0.81(0.78-0.86)$ & $<.001$ & $0.83(0.79-0.88)$ & $<.001$ \\
\hline \multicolumn{5}{|l|}{ Race/Ethnicity } \\
\hline Non-Hispanic White & Ref & & Ref & \\
\hline Non-Hispanic Black & $0.90(0.83-0.98)$ & .017 & $0.87(0.80-0.96)$ & .004 \\
\hline \multicolumn{5}{|l|}{ Facility area } \\
\hline Metropolitan & Ref & & - & - \\
\hline Urban & $1.03(0.96-1.11)$ & .383 & - & - \\
\hline Rural & $1.08(0.89-1.31)$ & .437 & - & - \\
\hline Unknown & $1.01(0.88-1.15)$ & .935 & - & - \\
\hline \multicolumn{5}{|l|}{ Facility location } \\
\hline East & Ref & & Ref & \\
\hline South & $1.03(0.96-1.11)$ & .339 & $1.08(1.00-1.17)$ & .057 \\
\hline Central & $1.26(1.17-1.36)$ & $<.001$ & $1.36(1.25-1.47)$ & $<.001$ \\
\hline West & $1.10(1.01-1.19)$ & .022 & $1.12(1.03-1.22)$ & .011 \\
\hline Medicaid & $0.87(0.78-0.97)$ & .013 & $0.91(0.81-1.02)$ & .100 \\
\hline Uninsured & $0.76(0.66-0.87)$ & $<.001$ & $0.76(0.66-0.88)$ & $<.001$ \\
\hline Other & $0.97(0.84-1.11)$ & .627 & $0.98(0.85-1.14)$ & .829 \\
\hline \multicolumn{5}{|c|}{ Distance to treatment facility } \\
\hline$\leq 40$ miles & Ref & & Ref & \\
\hline$>40$ miles & $0.85(0.80-0.90)$ & $<.001$ & $0.75(0.70-0.79)$ & $<.001$ \\
\hline Unknown/Missing & $0.76(0.60-0.95)$ & .018 & $1.26(0.53-2.98)$ & .601 \\
\hline \multicolumn{5}{|l|}{ Zip code education level } \\
\hline$\geq 21 \%$ & Ref & & Ref & \\
\hline $13 \%-20.9 \%$ & $1.03(0.95-1.12)$ & .445 & $1.03(0.94-1.12)$ & .561 \\
\hline $7 \%-12.9 \%$ & $1.05(0.97-1.13)$ & .233 & $1.00(0.91-1.10)$ & .954 \\
\hline$<7 \%$ & $1.07(0.99-1.15)$ & .108 & $1.00(0.90-1.12)$ & .961 \\
\hline Unknown & $0.79(0.62-0.99)$ & .050 & $0.60(0.17-2.06)$ & .416 \\
\hline
\end{tabular}


Table 1. Factors Associated With Receipt of Radiotherapy (cont.)

Univariate Analysis

Multivariate Analysis

\begin{tabular}{|c|c|c|c|c|}
\hline Factor & OR $(95 \% \mathrm{Cl})$ & $P$ Value & OR $(95 \% \mathrm{Cl})$ & $P$ Value \\
\hline \multicolumn{5}{|l|}{ Zip code income level, USD } \\
\hline$<\$ 38,000$ & Ref & & Ref & \\
\hline$\$ 38,000-\$ 47,999$ & $1.04(0.96-1.13)$ & .326 & $1.01(0.92-1.10)$ & .912 \\
\hline$\$ 48,000-\$ 62,999$ & $1.09(1.01-1.18)$ & .023 & $1.03(0.94-1.14)$ & .473 \\
\hline$\geq \$ 63,000$ & $1.07(1.00-1.15)$ & .066 & $0.99(0.89-1.10)$ & .899 \\
\hline Unknown & $0.83(0.66-1.04)$ & .102 & $0.87(0.36-2.11)$ & .762 \\
\hline \multicolumn{5}{|l|}{$\mathrm{CCl}$ score } \\
\hline 0 & Ref & & Ref & \\
\hline 1 & $0.87(0.81-0.93)$ & $<.001$ & $0.90(0.83-0.96)$ & .002 \\
\hline 2 & $0.77(0.67-0.89)$ & $<.001$ & $0.80(0.69-0.93)$ & .004 \\
\hline$\geq 3$ & $0.73(0.57-0.93)$ & .010 & $0.77(0.60-0.99)$ & .047 \\
\hline \multicolumn{5}{|l|}{ Primary tumor site } \\
\hline Extremity & Ref & & Ref & \\
\hline Head and neck & $0.55(0.50-0.61)$ & $<.001$ & $0.69(0.62-0.77)$ & $<.001$ \\
\hline Thorax & $0.53(0.49-0.58)$ & $<.001$ & $0.52(0.47-0.56)$ & $<.001$ \\
\hline Abdomen/Pelvis & $0.44(0.41-0.47)$ & $<.001$ & $0.42(0.39-0.44)$ & $<.001$ \\
\hline Other/NOS & $0.50(0.43-0.58)$ & $<.001$ & $0.54(0.46-0.63)$ & $<.001$ \\
\hline \multicolumn{5}{|l|}{ Histology } \\
\hline Unclassified & Ref & & Ref & \\
\hline Undifferentiated pleomorphic sarcoma & $1.16(1.06-1.25)$ & .001 & $1.13(1.03-1.23)$ & .007 \\
\hline Fibrosarcoma/Myxofibrosarcoma & $0.89(0.82-0.97)$ & .005 & $1.01(0.93-1.09)$ & .884 \\
\hline Liposarcoma & $0.97(0.90-1.05)$ & .416 & $1.01(0.93-1.10)$ & .786 \\
\hline Leiomyosarcoma & $0.54(0.50-0.58)$ & $<.001$ & $0.68(0.62-0.73)$ & $<.001$ \\
\hline Synovial sarcoma & $1.42(1.25-1.61)$ & $<.001$ & $1.45(1.26-1.66)$ & $<.001$ \\
\hline Angiosarcoma & $0.42(0.37-0.49)$ & $<.001$ & $0.55(0.48-0.64)$ & $<.001$ \\
\hline MPNST & $0.94(0.83-1.06)$ & .295 & $1.07(0.93-1.22)$ & .341 \\
\hline \multicolumn{5}{|l|}{ Tumor size } \\
\hline$\leq 5 \mathrm{~cm}$ & Ref & & Ref & \\
\hline $5.1-10 \mathrm{~cm}$ & $1.81(1.71-1.92)$ & $<.001$ & $1.81(1.71-1.93)$ & $<.001$ \\
\hline $10.1-15 \mathrm{~cm}$ & $1.90(1.76-2.04)$ & $<.001$ & $1.86(1.72-2.01)$ & $<.001$ \\
\hline$>15 \mathrm{~cm}$ & $1.44(1.33-1.56)$ & $<.001$ & $1.46(1.34-1.59)$ & $<.001$ \\
\hline \multicolumn{5}{|l|}{ Tumor grade } \\
\hline 2 & Ref & & Ref & \\
\hline 3 & $1.64(1.55-1.73)$ & $<.001$ & $1.50(1.41-1.60)$ & $<.001$ \\
\hline \multicolumn{5}{|l|}{ Receipt of chemotherapy } \\
\hline No & Ref & & Ref & \\
\hline Yes & $1.69(1.58-1.80)$ & $<.001$ & $1.39(1.29-1.49)$ & $<.001$ \\
\hline Unknown & $0.75(0.65-0.87)$ & $<.001$ & $0.71(0.61-0.82)$ & $<.001$ \\
\hline \multicolumn{5}{|l|}{ Year of diagnosis } \\
\hline 2004-2007 & Ref & & - & - \\
\hline 2008-2011 & $1.03(0.97-1.10)$ & .286 & - & - \\
\hline 2012-2015 & $1.03(0.97-1.09)$ & .384 & - & - \\
\hline
\end{tabular}

Abbreviations: $\mathrm{CCl}$, Charlson-Deyo comorbidity index; MPNST, malignant peripheral nerve sheath tumor; NOS, not otherwise specified; OR, odds ratio. 
Factors Associated With Receipt of Neoadjuvant Versus Adjuvant RT

Use of neoadjuvant RT increased over the study period, whereas use of adjuvant RT declined (Figure 2). Multivariable analysis revealed that notable factors associated with use of neoadjuvant RT included treatment at academic centers, larger tumor size $(>5 \mathrm{~cm})$, and tumors arising in the extremities (Table 2).

\section{Factors Associated With RT Modality}

Use of IMRT increased over the study period compared with 3DCRT (Figure 3). Multivariable analysis showed that important factors associated with IMRT use included treatment at academic centers, more recent diagnosis, larger tumor size $(>5 \mathrm{~cm})$, tumors arising in nonextremity locations (head and neck, thorax, and abdomen/pelvis), and commercial insurance coverage (Table 3).

\section{Discussion}

We used a national cancer registry to evaluate patterns of care in the treatment of high-grade STS. To our knowledge, this is the most comprehensive study to examine patterns of care regarding the use of RT in patients with high-grade STS using a real-world patient cohort. Given that randomized data have shown improvement in local control with the addition of RT, ${ }^{3-5}$ NCCN Guidelines for STS recommend the addition of neoadjuvant or adjuvant RT to surgery for patients with high-grade STS, particularly for larger tumors. ${ }^{2}$ However, our study shows that RT is potentially underused, with $42 \%$ of patients not receiving RT for stage II/III sarcomas. Even when we evaluated only patients with larger tumors $(>5 \mathrm{~cm}), 38 \%$ did not receive RT. Importantly, use of RT did not change over the study period. Interestingly, a prior SEER analysis of a similar cohort of patients with STS noted overall RT use of $47 \%$, although the study included lower-grade histologies. ${ }^{15}$

Moreover, concern remains that not all patients are equally considered for available therapies, given that we identified particular disparities in RT use among certain populations. In our study, we noted that Black patients, women, older patients, those with noncommercial insurance, and those with farther distance to treatment were less likely to receive RT, suggesting that these populations may also be vulnerable to omission of RT. Perhaps the most striking disparities we identified concerned the potential underuse of RT among patients who were Black and female, for which further investigation is warranted. Our study is consistent with several others that have noted disparities in the receipt of guideline-concordant cancer care and overall outcomes

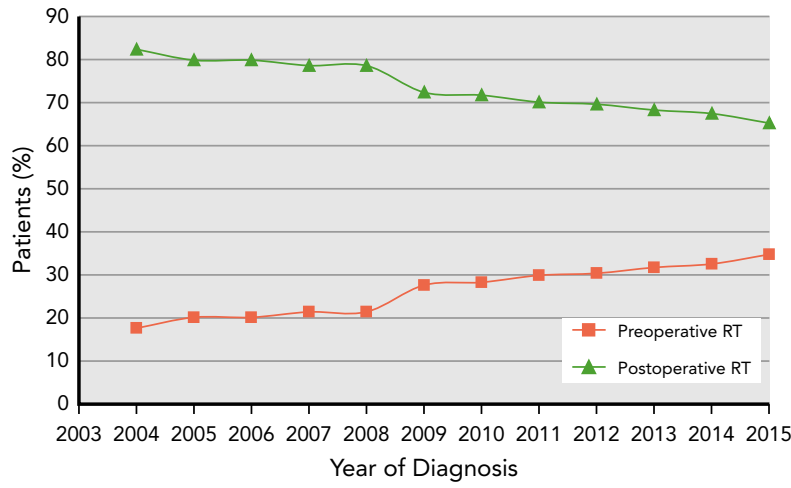

Figure 2. Trends in receipt of neoadjuvant or adjuvant RT. Abbreviation: RT, radiation therapy.

among Black patients due to a number of patient- and provider-driven factors. ${ }^{16-23}$ In addition, our study is consistent with several others that have revealed undertreatment of female patients compared with their male counterparts with respect to other disease sites and modalities of cancer care. ${ }^{24}$ We have previously shown that older populations are less likely to receive perioperative $\mathrm{RT}^{11}$ due to a number of potential factors that others have investigated, including physician-based factors such as hesitancy to recommend more-intensive treatment due to preconceived biases regarding patient frailty, and patient-related factors such as prioritization of immediate convenience and quality of life over long-term outcomes and survival. ${ }^{25-27}$

Patients with noncommercial insurance may encounter delays in obtaining medical attention or experience provider discrimination because of their insurance status, and several prior studies of other malignancies have shown that patients with noncommercial insurance such as Medicaid or who are uninsured are less likely to receive guideline-recommended care and frequently experience worse outcomes. ${ }^{28-31}$ It is possible that those with longer travel to their treatment facility may correspondingly undergo treatment in underresourced facilities where RT may not be easily incorporated into their treatment course. Moreover, given that some providers may not consider RT for patients with smaller tumors $(\leq 5 \mathrm{~cm})$, we specifically assessed whether these disparities persisted when only including patients with larger tumors $(>5 \mathrm{~cm})$ (supplemental eTable 2). Concordant with the larger cohort, in this subset, Black patients, women, older populations, those with noncommercial insurance, and those with farther distance to treatment remained less likely to receive RT. We identified that Hispanic patients were also less likely to receive RT. In addition, when specifically examining those with abdominal/ pelvic tumors, we noted that similar demographic and 


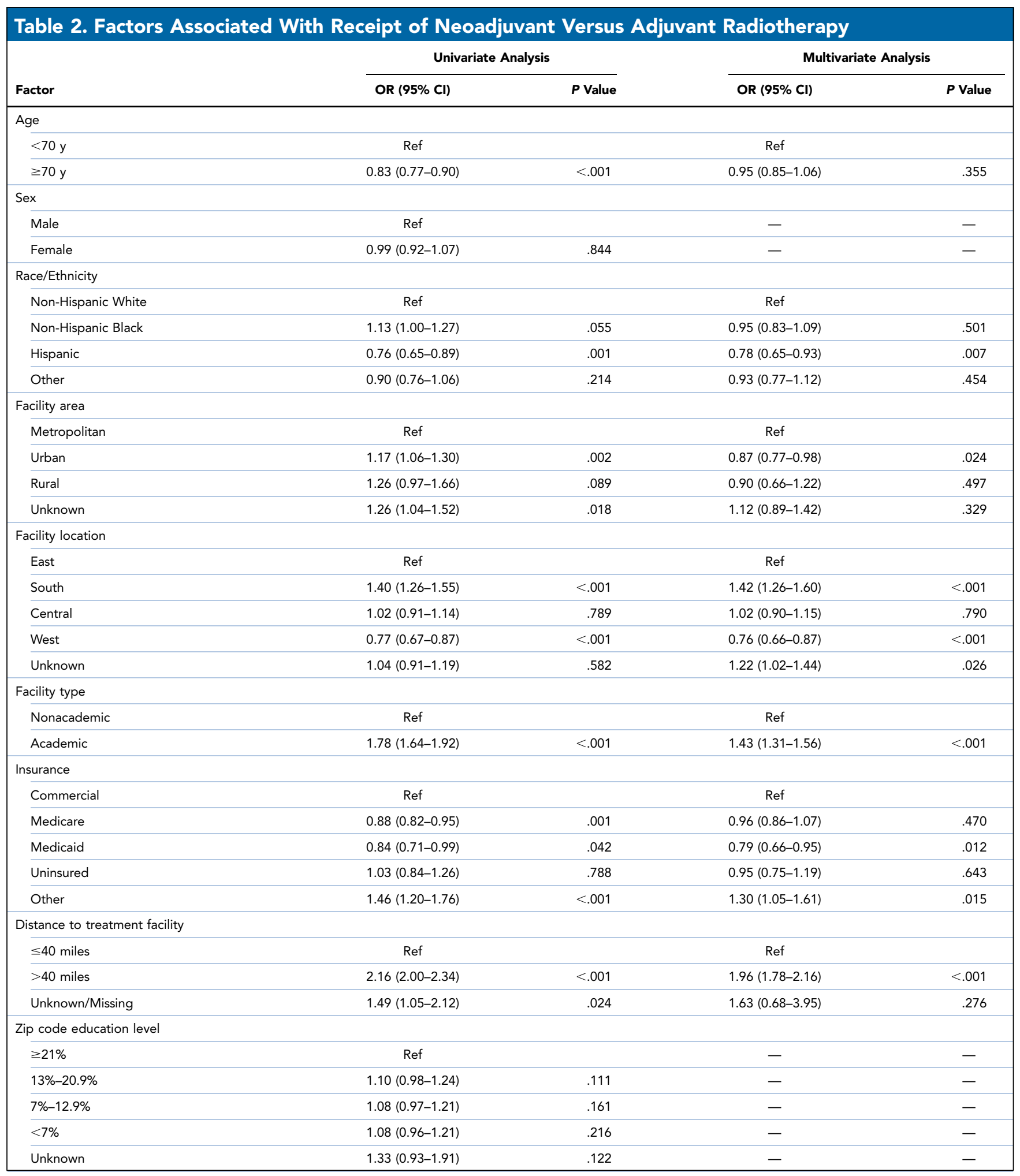




\section{Table 2. Factors Associated With Receipt of Neoadjuvant Versus Adjuvant Radiotherapy (cont.)}

Univariate Analysis

\section{Factor}

Zip code income level, USD

$<\$ 38,000$

$\$ 38,000-\$ 47,999$

$\$ 48,000-\$ 62,999$

$\geq \$ 63,000$

Unknown

$\mathrm{CCl}$ score

0

1

2

$\geq 3$

Primary tumor site

Extremity

Head and neck

Thorax

Abdomen/Pelvis

Other/NOS

Histology

\section{Unclassified}

Undifferentiated pleomorphic sarcoma

Fibrosarcoma/Myxofibrosarcoma

Liposarcoma

Leiomyosarcoma

Synovial sarcoma

Angiosarcoma

MPNST

Tumor size

$\leq 5 \mathrm{~cm}$

$5.1-10 \mathrm{~cm}$

$10.1-15 \mathrm{~cm}$

$>15 \mathrm{~cm}$

Tumor grade

2

3

Receipt of chemotherapy

No

Yes

Unknown

Year of diagnosis

2004-2007

2008-2011

2012-2015

OR $(95 \% \mathrm{Cl})$

Ref

0.95 (0.85-1.07)

0.92 (0.83-1.03)

$0.87(0.78-0.96)$

$1.10(0.77-1.55)$

\section{Ref}

1.03 (0.93-1.14)

0.99 (0.80-1.24)

$1.14(0.79-1.66)$

Ref

$0.18(0.14-0.23)$

$0.44(0.38-0.51)$

$0.58(0.52-0.64)$

$0.55(0.42-0.72)$

Ref

Ref

2.53 (2.29-2.80)

4.19 (3.74-4.70)

5.33 (4.72-6.01)

Ref

Ref

1.93 (1.78-2.09)

$1.12(0.88-1.42)$

$1.47(1.34-1.61)$

$1.93(1.77-2.11)$

$\begin{array}{lr}0.47(0.41-0.53) & <.001 \\ 0.59(0.53-0.67) & <.001 \\ 0.70(0.63-0.78) & <.001 \\ 0.53(0.47-0.60) & <.001 \\ 0.91(0.78-1.06) & .227 \\ 0.21(0.14-0.29) & <.001 \\ 0.34(0.28-0.43) & <.001\end{array}$

$1.22(1.11-1.34)$

$<.001$

0.98 (0.88-1.08)

.647

$<.001$

Ref

.350

1.53 (1.39-1.68)

$<.001$

$1.18(0.91-1.53)$

.207

Ref

OR $(95 \% \mathrm{Cl}) \quad P$ Value

Ref

$1.03(0.90-1.17)$

.697

.179

.099

.689

$-$

$-$

-

$<.001$

$<.001$

$<.001$

.003

Ref

$0.58(0.51-0.66)$

$<.001$

$<.001$

$<.001$

$<.001$

.901

$<.001$

$<.001$

\section{Ref}

$2.41(2.16-2.68)$

$<.001$

$<.001$

$<.001$
Multivariate Analysis

Abbreviations: CCl, Charlson-Deyo comorbidity index; MPNST, malignant peripheral nerve sheath tumor; NOS, not otherwise specified; OR, odds ratio. 
clinical factors were associated with RT use (supplemental eTable 3). It is important to note that the present study did not include retroperitoneal sarcomas, because the management of these tumors differs from STS of other anatomic subsites and it would be difficult to conclude that omission of RT in their management was a deviation from guideline-recommended treatment. Indeed, the role of RT in the management of retroperitoneal sarcomas remains controversial, ${ }^{32-36}$ especially in light of recent data from the STRASS trial showing overall no benefit of neoadjuvant RT. ${ }^{37}$

Treatment with neoadjuvant RT is often preferred, given the lower dose and smaller treatment volumes, which reduce the risk of long-term RT toxicity, such as fibrosis, edema, and joint issues, at the expense, however, of a higher risk of postsurgical wound complications. ${ }^{6}$ We examined practice patterns regarding timing of RT and found that, over the study period, there was an increase in neoadjuvant RT use, whereas use of adjuvant RT declined. This was especially pronounced in patients with larger tumors $(>5 \mathrm{~cm})$, more recent diagnosis, and treatment at academic centers. The observation that those with larger tumors are more likely to receive preoperative treatment is consistent with the ability to achieve a lower dose and smaller treatment fields with neoadjuvant RT. Moreover, our results showing that patients treated at academic medical centers and those with more recent diagnoses are more likely to receive neoadjuvant RT may be due to the tendency of academic institutions to incorporate into practice the recent randomized data showing a potentially favorable adverse effect profile for neoadjuvant treatment. All of this information is consistent with a shift in treatment paradigm regarding the timing of RT with respect to surgery for STS.

IMRT can offer a number of potential benefits, including favorable dosimetric characteristics that allow preferential sparing of bone, skin, soft tissues, and other organs at risk. Given the recent data highlighting the benefits of using IMRT in patients who receive $\mathrm{RT},{ }^{7,8}$ we sought to determine whether its use has been increasing in patients receiving RT in addition to surgery. Our study shows that, over the study period, there was an increase in IMRT use compared with 3DCRT. Notable predictors of receipt of IMRT included larger tumor size $(>5 \mathrm{~cm})$, tumors arising in nonextremity locations, more recent diagnosis, treatment at academic centers, and commercial insurance coverage. It is possible that patients with larger tumor sizes are more likely to receive IMRT because of the potentially favorable dosimetric profile and outcomes of IMRT, particularly when used for nonextremity locations. ${ }^{8,38}$ Moreover, patients were

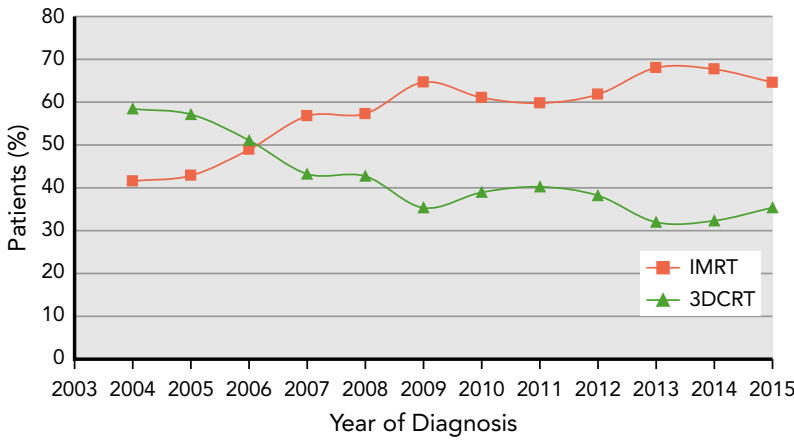

Figure 3. Trends in receipt of IMRT versus 3DCRT, by year. Abbreviations: 3DCRT, 3D conformal radiotherapy; IMRT, intensity-modulated radiotherapy.

more likely to receive IMRT at academic centers, which may tend to adopt changes in modality sooner than nonacademic centers, show increased comfort with use of IMRT, and benefit from more experience with regard to obtaining insurance approval for IMRT. Interestingly, lack of commercial insurance coverage was a negative predictor of receipt of IMRT, which can often be a more resource-intensive and expensive treatment course, though potentially more cost-effective. ${ }^{39}$

Strengths of the present study include a large, modern cohort of $>27,000$ patients treated for STS, adjustment for a range of patient- and facility-level variables, and inclusion of patients treated with both neoadjuvant and adjuvant RT and numerous modalities. Our study has several notable limitations, given its retrospective design and reliance on the content and accuracy of information included in the NCDB. In addition, there is inherent selection bias associated with the retrospective nature of this analysis. It is also possible that we were unable to account for several unmeasured confounders, such as patient preferences, physician attitudes, referral patterns, and quality of care received, which may have impacted patient selection and management.

\section{Conclusions}

Our findings show that RT for patients with high-grade STS remains potentially underused, despite national guidelines recommending the addition of RT to surgery. Moreover, our analysis also reflects that certain subgroups may be particularly vulnerable to omission of treatment, which could adversely impact outcomes. However, despite these findings, patients receiving RT were more likely to receive neoadjuvant RT and IMRT when treated, reflecting practice pattern change in line with emerging data suggesting the beneficial adverse effect profile of each. Given that treatment at academic and high-volume centers is associated 
Table 3. Factors Associated With Receipt of Intensity-Modulated Radiotherapy

\begin{tabular}{|c|c|c|c|c|}
\hline Factor & \multicolumn{2}{|c|}{ Univariate Analysis } & \multicolumn{2}{|c|}{ Multivariate Analysis } \\
\hline \multicolumn{5}{|l|}{ Age } \\
\hline$\geq 70 y$ & $0.80(0.71-0.91)$ & .001 & $0.93(0.78-1.11)$ & .433 \\
\hline \multicolumn{5}{|l|}{ Sex } \\
\hline Female & $1.01(0.90-1.13)$ & .869 & - & - \\
\hline \multicolumn{5}{|l|}{ Race/Ethnicity } \\
\hline Non-Hispanic White & Ref & & Ref & \\
\hline Non-Hispanic Black & $1.06(0.87-1.29)$ & .582 & $1.01(0.81-1.27)$ & .905 \\
\hline Hispanic & $1.46(1.12-1.90)$ & .005 & $1.53(1.14-2.04)$ & .004 \\
\hline Urban & $0.87(0.73-1.03)$ & .111 & - & - \\
\hline Rural & $0.84(0.51-1.36)$ & .469 & - & - \\
\hline Unknown & $1.07(0.76-1.52)$ & .696 & - & - \\
\hline \multicolumn{5}{|l|}{ Facility location } \\
\hline East & Ref & & Ref & \\
\hline South & $0.94(0.79-1.12)$ & .505 & $1.03(0.85-1.24)$ & .756 \\
\hline Central & $0.64(0.54-0.76)$ & $<.001$ & $0.65(0.54-0.79)$ & $<.001$ \\
\hline West & $0.61(0.50-0.75)$ & $<.001$ & $0.61(0.49-0.75)$ & $<.001$ \\
\hline Unknown & $0.98(0.79-1.22)$ & .868 & $1.04(0.80-1.36)$ & .754 \\
\hline \multicolumn{5}{|l|}{ Facility type } \\
\hline Uninsured & $0.74(0.52-1.05)$ & .089 & $0.56(0.39-0.82)$ & .003 \\
\hline Other & $0.95(0.66-1.38)$ & .790 & $0.92(0.62-1.36)$ & .676 \\
\hline \multicolumn{5}{|c|}{ Distance to treatment facility } \\
\hline$\leq 40$ miles & Ref & & Ref & \\
\hline$>40$ miles & $1.32(1.15-1.52)$ & $<.001$ & $1.22(1.04-1.43)$ & .017 \\
\hline Unknown/Missing & $1.14(0.52-2.51)$ & .737 & $2.09(0.15-29.44)$ & .585 \\
\hline \multicolumn{5}{|l|}{ Zip code education level } \\
\hline$\geq 21 \%$ & Ref & & - & - \\
\hline $13 \%-20.9 \%$ & $1.22(1.00-1.49)$ & .051 & - & - \\
\hline $7 \%-12.9 \%$ & $1.08(0.90-1.30)$ & .396 & - & - \\
\hline$<7 \%$ & $1.05(0.87-1.27)$ & .596 & - & - \\
\hline Unknown & $1.17(0.53-2.61)$ & .692 & - & - \\
\hline
\end{tabular}




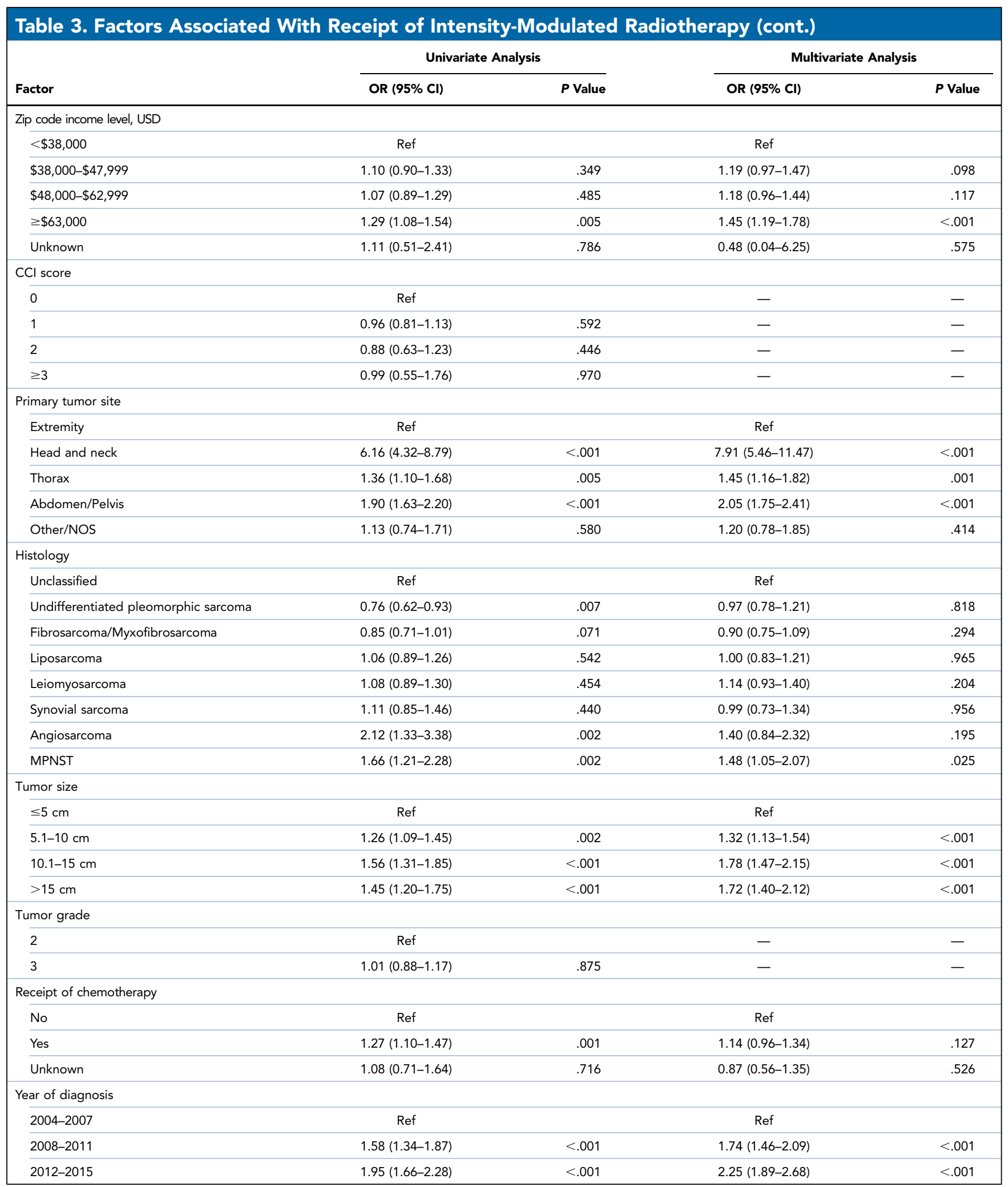

Abbreviations: $\mathrm{CCl}$, Charlson-Deyo comorbidity index; MPNST, malignant peripheral nerve sheath tumor; NOS, not otherwise specified; OR, odds ratio. 
with improved outcomes in patients with both STS and other malignancies, ${ }^{40-44}$ we were interested in assessing whether RT use was increased at academic centers. Although we noted no difference in overall RT use, academic centers were more likely to use both neoadjuvant RT and IMRT. In light of these data, future strategies aimed at making RT more accessible, convenient, and cost-conscious are certainly warranted. Recent studies have suggested that shorter RT regimens may have an acceptable toxicity profile and increase the likelihood of neoadjuvant use, ${ }^{45}$ which is encouraging for both patients and providers. Further work evaluating access to and quality of treatment is warranted to improve outcomes in this patient population.

Submitted January 23, 2020; accepted for publication July 22, 2020. Published online February 8, 2021.

Author contributions: Study concept and design: Reddy, Jain, Shabason Data analysis and interpretation: All authors. Manuscript preparation: All authors. Critical revision: All authors.

Disclosures: The authors have disclosed that they have not received any financial consideration from any person or organization to support the preparation, analysis, results, or discussion of this article.

Correspondence: Jacob E. Shabason, MD, MTR, Department of Radiation Oncology, Perelman School of Medicine at the University of Pennsylvania, 3400 Civic Center Boulevard, Philadelphia, PA 19104

Email: jacob.shabason@pennmedicine.upenn.edu

\section{References}

1. Siegel RL, Miller KD, Jemal A. Cancer statistics, 2019. CA Cancer J Clin 2019;69:7-34

2. von Mehren M, Kane JM, Bui MM, et al. NCCN Clinical Practice Guidelines in Oncology: Soft Tissue Sarcoma. Version 1.2021. Accessed November 10, 2020. To view the most recent version, visit NCCN.org

3. Yang JC, Chang AE, Baker AR, et al. Randomized prospective study of the benefit of adjuvant radiation therapy in the treatment of soft tissue sarcomas of the extremity. J Clin Oncol 1998;16:197-203.

4. Pisters PW, Harrison LB, Leung DH, et al. Long-term results of a prospective randomized trial of adjuvant brachytherapy in soft tissue sarcoma. J Clin Oncol 1996;14:859-868.

5. Rosenberg SA, Tepper J, Glatstein E, et al. The treatment of softtissue sarcomas of the extremities: prospective randomized evaluations of (1) limb-sparing surgery plus radiation therapy compared with amputation and (2) the role of adjuvant chemotherapy. Ann Surg 1982; 196:305-315.

6. O'Sullivan B, Davis AM, Turcotte R, et al. Preoperative versus postoperative radiotherapy in soft-tissue sarcoma of the limbs: a randomised trial. Lancet 2002;359:2235-2241.

7. Wang $D$, Zhang $\mathrm{Q}$, Eisenberg $\mathrm{BL}$, et al. Significant reduction of late toxicities in patients with extremity sarcoma treated with image-guided radiation therapy to a reduced target volume: results of Radiation Therapy Oncology Group RTOG-0630 Trial. J Clin Oncol 2015;33:2231-2238.

8. Folkert MR, Singer S, Brennan MF, et al. Comparison of local recurrence with conventional and intensity-modulated radiation therapy for primary soft-tissue sarcomas of the extremity. J Clin Oncol 2014;32:3236-3241.

9. Horton JK, Gleason JF Jr, Klepin HD, et al. Age-related disparities in the use of radiotherapy for treatment of localized soft tissue sarcoma. Cancer 2011;117:4033-4040.

10. Hoven-Gondrie ML, Bastiaannet $\mathrm{E}, \mathrm{Ho}$ VKY, et al. Worse survival in elderly patients with extremity soft-tissue sarcoma. Ann Surg Oncol 2016;23: 2577-2585.

11. Venigalla S, Carmona R, VanderWalde N, et al. Disparities in perioperative radiation therapy use in elderly patients with soft-tissue sarcoma. Int J Radiat Oncol Biol Phys 2018;102:155-165.

12. American College of Surgeons. National Cancer Database. Accessed November 19, 2020. Accessed January 22, 2020. Available at: https:// www.facs.org/Quality-Programs/Cancer/NCDB

13. Bilimoria KY, Stewart AK, Winchester DP, et al. The National Cancer Data Base: a powerful initiative to improve cancer care in the United States. Ann Surg Oncol 2008;15:683-690.

14. Deyo RA, Cherkin DC, Ciol MA. Adapting a clinical comorbidity index for use with ICD-9-CM administrative databases. J Clin Epidemiol 1992;45:613-619.

15. Koshy M, Rich SE, Mohiuddin MM. Improved survival with radiation therapy in high-grade soft tissue sarcomas of the extremities: a SEER analysis. Int J Radiat Oncol Biol Phys 2010;77:203-209.

16. Blom EF, ten Haaf $K$, Arenberg DA, et al. Disparities in receiving guidelineconcordant treatment of lung cancer in the United States. Ann Am Thorac Soc 2020;17:186-194.

17. Lin JJ, Mhango G, Wall MM et al. Cultural factors associated with racia disparities in lung cancer care. Ann Am Thorac Soc 2014;11:489-495.

18. Nocon CC, Ajmani GS, Bhayani MK. A contemporary analysis of racial disparities in recommended and received treatment of head and neck cancer. Cancer 2020;126:381-389.

19. Naghavi AO, Echevarria MI, Strom TJ, et al. Treatment delays, race, and outcomes in head and neck cancer. Cancer Epidemiol 2016;45: $18-25$.

20. Al-Othman MOF, Morris CG, Logan HL, et al. Impact of race on outcome after definitive radiotherapy for squamous cell carcinoma of the head and neck. Cancer 2003;98:2467-2472.

21. Carroll WR, Kohler CL, Carter VL, et al. Barriers to early detection and treatment of head and neck squamous cell carcinoma in African American men. Head Neck 2009;31:1557-1562.

22. Dilling TJ, Bae K, Paulus R, et al. Impact of gender, partner status, and race on locoregional failure and overall survival in head and neck cancer patients in three Radiation Therapy Oncology Group trials. Int J Radiat Oncol Biol Phys 2011;81:e101-109.

23. Du XL, Liu CC. Racial/ethnic disparities in socioeconomic status, diagnosis, treatment and survival among Medicare-insured men and women with head and neck cancer. J Health Care Poor Underserved 2010;21:913-930.

24. Park A, Alabaster A, Shen $\mathrm{H}$, et al. Undertreatment of women with locoregionally advanced head and neck cancer. Cancer 2019;125:3033-3039.

25. Foster JA, Salinas GD, Mansell D, et al. How does older age influence oncologists' cancer management? Oncologist 2010;15:584-592.

26. Javid $\mathrm{SH}$, Unger JM, Gralow JR, et al. A prospective analysis of the influence of older age on physician and patient decision-making when considering enrollment in breast cancer clinical trials (SWOG S0316) Oncologist 2012;17:1180-1190.

27. Townsley CA, Selby R, Siu LL. Systematic review of barriers to the recruitment of older patients with cancer onto clinical trials. J Clin Oncol 2005;23:3112-3124.

28. Harlan LC, Greene AL, Clegg LX, et al. Insurance status and the use of guideline therapy in the treatment of selected cancers. J Clin Oncol 2005 23:9079-9088.

29. Jain V, Venigalla S, Sebro RA, et al. Association of health insurance status with presentation, treatment and outcomes in soft tissue sarcoma. Cancer Med 2019;8:6295-6304.

30. Naghavi AO, Echevarria MI, Grass GD, et al. Having Medicaid insurance negatively impacts outcomes in patients with head and neck malignancies. Cancer 2016;122:3529-3537

31. Parikh RR, Grossbard ML, Green BL, et al. Disparities in survival by insurance status in patients with Hodgkin lymphoma. Cancer 2015 121:3515-3524.

32. Gronchi A, Strauss DC, Miceli R, et al. Variability in patterns of recurrence after resection of primary retroperitoneal sarcoma (RPS): a report on 1007 patients from the multi-institutional collaborative RPS Working Group. Ann Surg 2016;263:1002-1009.

33. Nussbaum DP, Rushing CN, Lane WO, et al. Preoperative or postoperative radiotherapy versus surgery alone for retroperitoneal sarcoma: a casecontrol, propensity score-matched analysis of a nationwide clinical oncology database. Lancet Oncol 2016;17:966-975. 
34. Heslin MJ, Lewis JJ, Nadler E, et al. Prognostic factors associated with long-term survival for retroperitoneal sarcoma: implications for management. J Clin Oncol 1997;15:2832-2839.

35. Stoeckle E, Coindre JM, Bonvalot S, et al. Prognostic factors in retroperitoneal sarcoma: a multivariate analysis of a series of 165 patients of the French Cancer Center Federation Sarcoma Group. Cancer 2001;92:359-368.

36. Pawlik TM, Pisters PWT, Mikula L, et al. Long-term results of two prospective trials of preoperative external beam radiotherapy for localized intermediate- or high-grade retroperitoneal soft tissue sarcoma. Ann Surg Oncol 2006;13:508-517.

37. Bonvalot S, Gronchi A, Le Pechoux C, et al. STRASS (EORTC 62092): a phase III randomized study of preoperative radiotherapy plus surgery versus surgery alone for patients with retroperitoneal sarcoma [abstract]. J Clin Oncol 2019;37(Suppl):Abstract 11001.

38. Alektiar KM, Brennan MF, Singer S. Local control comparison of adjuvant brachytherapy to intensity-modulated radiotherapy in primary high-grade sarcoma of the extremity. Cancer 2011;117:3229-3234.

39. Richard P, Phillips M, Smith W, et al. Cost-effectiveness analysis of intensity modulated radiation therapy versus 3-dimensional conformal radiation therapy for preoperative treatment of extremity soft tissue sarcomas. Int J Radiat Oncol Biol Phys 2016;95: 999-1008

40. Venigalla $\mathrm{S}, \mathrm{Nead} K \mathrm{KT}$, Sebro $\mathrm{R}$, et al. Association between treatment at high-volume facilities and improved overall survival in soft tissue sarcomas. Int J Radiat Oncol Biol Phys 2018;100:1004-1015.

41. Wuthrick EJ, Zhang Q, Machtay M, et al. Institutional clinical trial accrual volume and survival of patients with head and neck cancer. J Clin Oncol 2015;33:156-164.

42. Chien $\mathrm{CR}$, Lin $\mathrm{HW}$, Yang $\mathrm{CH}$, et al. High case volume of radiation oncologists is associated with better survival of nasopharyngeal carcinoma patients treated with radiotherapy: a multifactorial cohort analysis. Clin Otolaryngol 2011;36:558-565

43. Sharma A Schwartz SM, Méndez E. Hospital volume is associated with survival but not multimodality therapy in Medicare patients with advanced head and neck cancer. Cancer 2013;119:1845-1852.

44. Naghavi AO, Echevarria MI, Strom TJ, et al. Patient choice for highvolume center radiation impacts head and neck cancer outcome. Cancer Med 2018;7:4964-4979.

45. Kalbasi A, Kamrava M, Chu FI, et al. A phase II trial of 5-day neoadjuvant radiotherapy for patients with high-risk primary soft tissue sarcoma. Clin Cancer Res 2020;26:1829-1836.

\title{
Explore Oncology From Every Angle
}

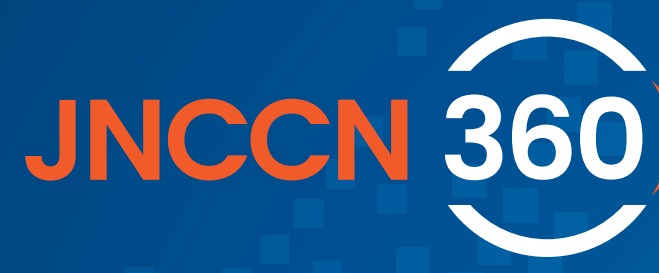

\author{
The Hub for Disease-Specific Clinical Information \\ > JNCCN Spotlights: \\ exclusive commentary \\ about current therapies \\ Video interviews with experts \\ $>$ Links to professional \\ and patient resources \\ $>$ Summaries of news \\ and medical literature
}

JNCCN360.org
YARBORSIDE

The nexus of knowledge
National

Comprehensiv Cancer 
Supplemental online content for:

\section{Radiotherapy Remains Underused in the Treatment of Soft-Tissue Sarcomas: Disparities in Practice Patterns in the United States}

Vishruth K. Reddy, MD, PhD; Varsha Jain, MD, PhD; Sriram Venigalla, MD; William P. Levin, MD; Robert J. Wilson II, MD; Kristy L. Weber, MD; Anusha Kalbasi, MD; Ronnie A. Sebro, MD, PhD; and Jacob E. Shabason, MD, MTR

J Natl Compr Canc Netw 2021;19(3):295-306

eFigure 1: CONSORT Diagram of the Patient Cohort

eTable 1: Baseline Patient Characteristics

eTable 2: Factors Associated With Receipt of Radiotherapy in Patients With Tumors $>5 \mathrm{~cm}$

eTable 3: Factors Associated With Receipt of Radiotherapy in Patients With Abdominal/Pelvic Tumors 


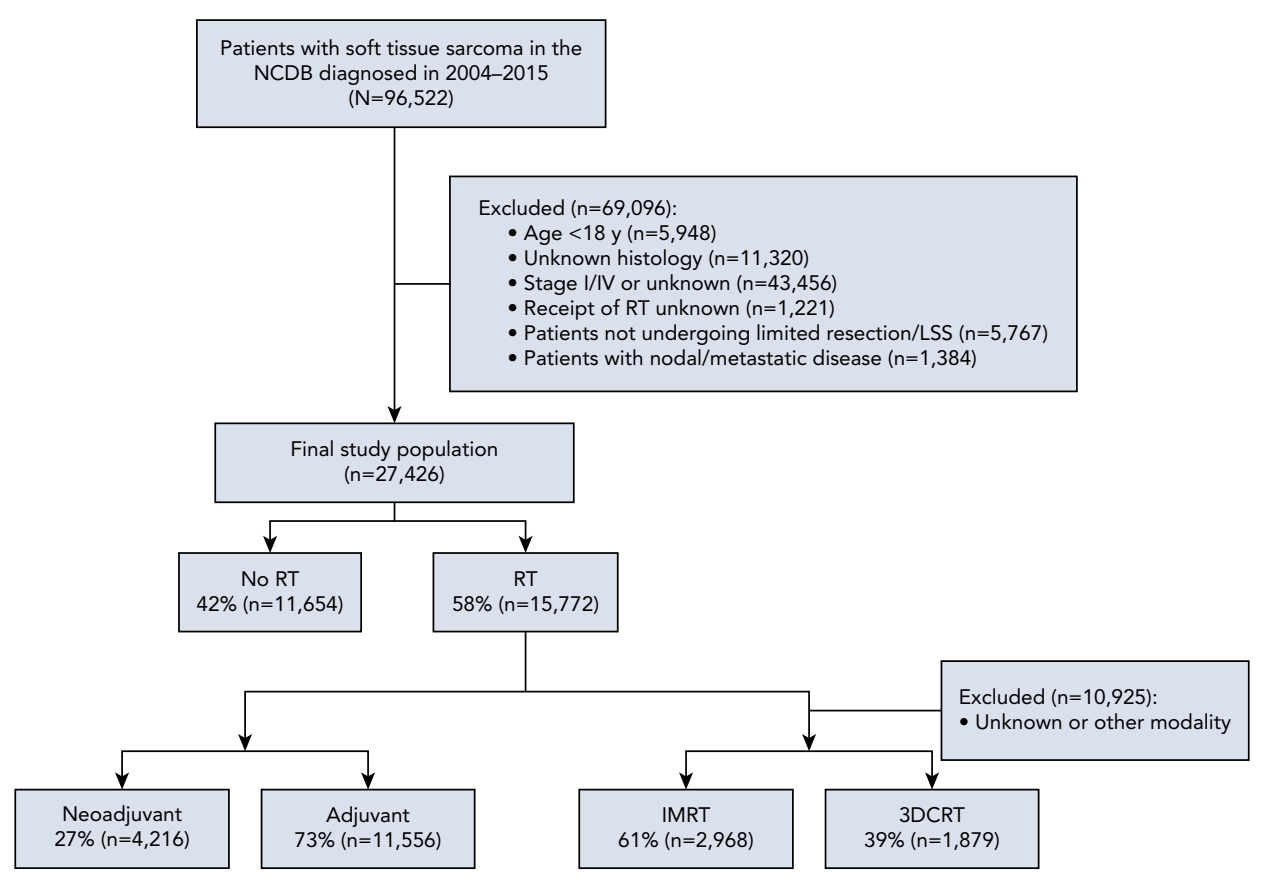

eFigure 1. CONSORT diagram of the patient cohort.

Abbreviation: 3DCRT, 3D conformal radiotherapy; IMRT, intensity-modulated radiotherapy; LSS, limb-sparing surgery; NCDB, National Cancer Database; RT, radiotherapy. 


\section{eTable 1. Baseline Patient Characteristics}

\begin{tabular}{|c|c|c|c|c|}
\hline Characteristic & No (\%) & Yes (\%) & Total (\%) & $\begin{array}{l}\text { Chi- } \\
\text { Square } \\
P \text { Value }\end{array}$ \\
\hline Total, $n$ & $11,654(42)$ & $15,772(58)$ & $27,426(100)$ & \\
\hline Age & & & & $<.001$ \\
\hline$<70 y$ & $7,308(63)$ & $10,462(66)$ & $17,770(65)$ & \\
\hline$\geq 70 y$ & $4,346(37)$ & $5,310(34)$ & $9,656(35)$ & \\
\hline Sex & & & & $<.001$ \\
\hline Male & $5,952(51)$ & $8,857(56)$ & $14,809(54)$ & \\
\hline Female & $5,702(49)$ & 6,915 (44) & $12,617(46)$ & \\
\hline Race/Ethnicity & & & & $<.001$ \\
\hline $\begin{array}{l}\text { Non-Hispanic } \\
\text { White }\end{array}$ & 9,205 (79) & $12,686(80)$ & $21,891(80)$ & \\
\hline $\begin{array}{l}\text { Non-Hispanic } \\
\text { Black }\end{array}$ & $1,145(10)$ & $1,427(9)$ & $2,572(9)$ & \\
\hline Hispanic & $732(6)$ & $910(6)$ & $1,642(6)$ & \\
\hline Other & $572(5)$ & $749(5)$ & $1,321(5)$ & \\
\hline Facility area & & & & .007 \\
\hline Metropolitan & $9,549(82)$ & $12,851(81)$ & $22,400(82)$ & \\
\hline Urban & $1,549(13)$ & $2,151(14)$ & $3,700(13)$ & \\
\hline Rural & $174(1)$ & $253(2)$ & $427(2)$ & \\
\hline Unknown & $382(3)$ & $517(3)$ & $899(3)$ & \\
\hline Facility location & & & & $<.001$ \\
\hline East & $2,281(20)$ & $2,849(18)$ & 5,130 (19) & \\
\hline South & $3,621(31)$ & $4,680(30)$ & $8,301(30)$ & \\
\hline Central & $2,392(21)$ & $3,774(24)$ & $6,166(22)$ & \\
\hline West & $1,880(16)$ & $2,582(16)$ & $4,462(16)$ & \\
\hline Unknown & $1,480(13)$ & $1,887(12)$ & $3,367(12)$ & \\
\hline Facility type & & & & $<.001$ \\
\hline Nonacademic & $4,880(42)$ & $6,548(42)$ & $11,428(42)$ & \\
\hline Academic & $5,294(45)$ & 7,337 (47) & $12,631(46)$ & \\
\hline Unknown & $1,480(13)$ & $1,887(12)$ & $3,367(12)$ & \\
\hline Insurance & & & & $<.001$ \\
\hline Commercial & $5,089(44)$ & $7,608(48)$ & $12,697(46)$ & \\
\hline Medicare & 5,153 (44) & $6,348(40)$ & $11,501(42)$ & \\
\hline Medicaid & $649(6)$ & $846(5)$ & $1,495(5)$ & \\
\hline Uninsured & $420(4)$ & $475(3)$ & $895(3)$ & \\
\hline Other & $343(3)$ & $495(3)$ & $838(3)$ & \\
\hline \multicolumn{2}{|c|}{ Distance to treatment facility } & & & $<.001$ \\
\hline$\leq 40$ miles & $8,279(71)$ & $11,734(74)$ & $20,013(73)$ & \\
\hline$>40$ miles & $3,234(28)$ & $3,887(25)$ & $7,121(26)$ & \\
\hline Unknown/Missing & $141(1)$ & $151(1)$ & $292(1)$ & \\
\hline
\end{tabular}

(continued)

\section{eTable 1. Baseline Patient Characteristics (cont.)}

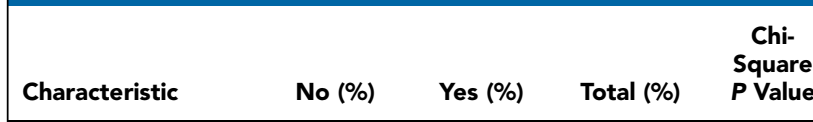

Zip code education level

$\geq 21 \% \quad 1,750$ (15) $\quad 2,282$ (14) 4,032 (15)

$13 \%-20.9 \% \quad 2,780(24) \quad 3,739(24) \quad 6,519(24)$

\begin{tabular}{lllll}
\hline $7 \%-12.9 \%$ & $3,877(33)$ & $5,291(34)$ & $9,168(33)$
\end{tabular}

$<7 \% \quad 3,103(27) \quad 4,312(27) \quad 7,415(27)$

Unknown $\quad 144(1) \quad 148(1) \quad 292(1)$

Zip code income level, USD

\begin{tabular}{lcrr}
\hline$<\$ 38,000$ & $1,843(16)$ & $2,363(15)$ & $4,206(15)$ \\
\hline$\$ 38,000-\$ 47,999$ & $2,610(22)$ & $3,482(22)$ & $6,092(22)$ \\
\hline$\$ 48,000-\$ 62,999$ & $3,034(26)$ & $4,253(27)$ & $7,287(27)$ \\
$\geq \$ 63,000$ & $4,014(34)$ & $5,512(35)$ & $9,526(35)$ \\
\hline Unknown & $153(1)$ & $162(1)$ & $315(1)$
\end{tabular}

$\mathrm{CCl}$ score

$0 \quad 9,248(79) \quad 12,931(82) \quad 22,179(81)$

$1 \quad 1,881(16) \quad 2,282(14) \quad 4,163(15)$

$2 \quad 394(3) \quad 426(3) \quad 820(3)$

$\geq 3 \quad 131(1) \quad 133(1) \quad 264(1)$

Primary tumor site

Head and neck $\quad 819(7) \quad 839(5) \quad 1,658(6)$

Upper extremity $\quad 1,549(13) \quad 2,669(17) \quad 4,218(15)$

Lower extremity $\quad 4,070(35) \quad 7,751(49) \quad 11,821(43)$

Thorax $\quad 1,327(11) \quad 1,304(8) \quad 2,631(10)$

Abdomen/Pelvis $\quad 3,535(30) \quad 2,880(18) \quad 6,415(23)$

Other/NOS $\quad 354$ (3) $329(2) \quad 683(2)$

Histology

$<.001$

Unclassified $\quad 3,326(29) \quad 5,076(32) \quad 8,402(31)$

Undifferentiated $\quad 1,240(11) \quad 2,186(14) \quad 3,426(12)$ pleomorphic

sarcoma

Fibrosarcoma/ $\quad 1,559(13) \quad 2,123(13) \quad 3,682(13)$

Myxofibrosarcoma

Liposarcoma $\quad 1,691(15) \quad 2,501(16) \quad 4,192(15)$

Leiomyosarcoma $\quad 2,401(21) \quad 1,987(13) \quad 4,388(16)$

Synovial sarcoma $\quad 393(3) \quad 852(5) \quad 1,245(5)$

Angiosarcoma $\quad 569(5) \quad 369(2) \quad 938(3)$

MPNST $\quad 475(4) \quad 678(4) \quad 1,153(4)$

\begin{tabular}{lllll}
\hline \multicolumn{1}{l}{ Tumor size } & & & & $<.001$ \\
\hline$\leq 5 \mathrm{~cm}$ & $5,084(44)$ & $4,843(31)$ & $9,927(36)$ & \\
\hline $5.1-10 \mathrm{~cm}$ & $3,509(30)$ & $6,050(38)$ & $9,559(35)$ & \\
\hline $10.1-15 \mathrm{~cm}$ & $1,558(13)$ & $2,815(18)$ & $4,373(16)$ \\
\hline $15 \mathrm{~cm}$ & $1,503(13)$ & $2,064(13)$ & $3,567(13)$
\end{tabular}

(continued on next page) 


\begin{tabular}{|l|cccc|}
\hline eTable 1. Baseline Patient Characteristics (cont.) \\
\hline Characteristic & No (\%) & Yes (\%) & Total (\%) & $\begin{array}{c}\text { Chi- } \\
\text { Square } \\
\text { P Value }\end{array}$ \\
\hline Tumor grade & & & & $<.001$ \\
\hline 2 & $3,335(29)$ & $3,105(20)$ & $6,440(23)$ & \\
\hline 3 & $8,319(71)$ & $12,667(80)$ & $20,986(77)$ & \\
\hline Clinical stage & & & & $<.001$ \\
\hline II & $5,084(44)$ & $4,843(31)$ & $9,927(36)$ & \\
\hline III & $6,570(56)$ & $10,929(69)$ & $17,499(64)$ & \\
\hline Receipt of chemotherapy & & & & $<.001$ \\
\hline No & $9,718(83)$ & $12,152(77)$ & $21,870(80)$ & \\
\hline Yes & $1,542(13)$ & $3,250(21)$ & $4,792(17)$ & \\
\hline Unknown & $394(3)$ & $370(2)$ & $764(3)$ & \\
\hline Year of diagnosis & & & & \\
\hline 2004 & $869(7)$ & $1,078(7)$ & $1,947(7)$ & \\
\hline 2005 & $902(8)$ & $1,216(8)$ & $2,118(8)$ & \\
\hline 2006 & $911(8)$ & $1,221(8)$ & $2,132(8)$ & \\
\hline 2007 & $944(8)$ & $1,294(8)$ & $2,238(8)$ & \\
\hline 2008 & $950(8)$ & $1,339(8)$ & $2,289(8)$ & \\
\hline 2009 & $1,053(9)$ & $1,390(9)$ & $2,443(9)$ & \\
\hline 2010 & $972(8)$ & $1,248(8)$ & $2,220(8)$ & \\
\hline 2011 & $990(8)$ & $1,301(8)$ & $2,178(8)$ & \\
\hline 2012 & $1,111(10)$ & $1,510(10)$ & $2,621(10)$ & \\
\hline 2013 & $1,274(8)$ & $2,199(8)$ & \\
\hline 2014 & $1,374(9)$ & $2,364(9)$ & \\
\hline
\end{tabular}

Abbreviations: $\mathrm{CCl}$, Charlson-Deyo comorbidity index; MPNST, malignant peripheral nerve sheath tumor; NOS, not otherwise specified. 


\section{eTable 2. Factors Associated With Receipt of Radiotherapy in Patients With Tumors $>5 \mathrm{~cm}$}

Univariate Analysis

\section{Factor}

Age

$$
<70 \mathrm{y}
$$$$
\geq 70 \mathrm{y}
$$

Sex

$$
\text { Male }
$$

Female

Race/Ethnicity

Non-Hispanic White
Non-Hispanic Black
Hispanic
Other

\section{Ref}

$0.86(0.78-0.95)$

$0.83(0.73-0.94)$

$0.88(0.76-1.01)$

OR $(95 \% \mathrm{CI}) \quad$ P Value

$$
\text { Ref }
$$

$0.81(0.76-0.86)$

$$
\text { Ref }
$$

$0.80(0.76-0.86)$

$$
<.001
$$

Multivariate Analysis

OR $(95 \% \mathrm{Cl})$

Ref

$0.85(0.77-0.93)$

$<.001$

Ref

$0.82(0.77-0.88) \quad<.001$

Facility area

$$
\text { Metropolitan }
$$

Urban

Rural

Unknown

Facility location

East
South
Central

Central

West

Unknown

Facility type

Nonacademic

Academic

Insurance

Commercial

Medicare

Medicaid

Uninsured

Other

Distance to treatment facility

$$
\begin{aligned}
& \leq 40 \text { miles } \\
& >40 \text { miles }
\end{aligned}
$$

Unknown/Missing

Zip code education level

$\geq 21 \%$

13\%-20.9\%

$7 \%-12.9 \%$

$<7 \%$

Unknown
Ref

$1.08(1.02-1.16)$

$$
\text { Ref }
$$

$1.02(0.93-1.11)$

$1.24(1.13-1.37)$

$0.99(0.90-1.10)$

$1.09(0.97-1.22)$

$$
\text { Ref }
$$

$0.76(0.72-0.82)$

$0.81(0.71-0.92)$

$0.68(0.58-0.81)$

$0.92(0.77-1.11)$

$$
\text { Ref }
$$

$0.86(0.80-0.92)$

$0.76(0.58-1.00)$

Ref

$1.10(1.00-1.22)$

$1.14(1.04-1.25)$

$1.17(1.06-1.28)$

0.85 (0.64-1.12)
Ref

$0.87(0.78-0.98) \quad .017$

$0.85(0.74-0.98)$

$0.86(0.74-1.00)$

.022

.048
.617

.677

.885

.694
$<.001$
.893
.149

.015

Ref

$1.05(0.98-1.13)$

.172

Ref

$0.86(0.79-0.95)$

$0.91(0.79-1.04)$

$0.69(0.58-0.83)$

$0.95(0.78-1.15)$

-

-

$-$

$-$

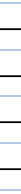

$-$




\section{eTable 2. Factors Associated With Receipt of Radiotherapy in Patients With Tumors $>5 \mathrm{~cm}$ (cont.)}

Univariate Analysis

Factor

Zip code income level, USD

$<\$ 38,000$

\section{$\$ 38,000-\$ 47,999$}

$\$ 48,000-\$ 62,999$

$\geq \$ 63,000$

Unknown

$\mathrm{CCl}$ score

$\frac{0}{1}$
2
$\geq 3$

\section{OR $(95 \% \mathrm{Cl})$}

Ref

$1.05(0.95-1.16)$

$1.09(0.99-1.20)$

$1.10(1.00-1.21)$

$0.84(0.64-1.11)$

Ref

$0.80(0.74-0.87)$

$0.75(0.63-0.90)$

$0.60(0.45-0.80)$
Primary tumor site

Extremity
Head and neck
Thorax

Abdomen/Pelvis

Other/NOS

\section{Ref}

$0.58(0.48-0.69)$

$0.47(0.43-0.53)$

$0.34(0.32-0.37)$

$0.37(0.31-0.45)$

Ref

Unclassified

$1.11(0.99-1.23)$

Undifferentiated pleomorphic sarcoma

Fibrosarcoma/Myxofibrosarcoma

Liposarcoma

Leiomyosarcoma

Synovial sarcoma

Angiosarcoma

MPNST

Tumor size

$10.1-15 \mathrm{~cm}$

$>15 \mathrm{~cm}$

$1.05(0.97-1.13)$

$0.80(0.74-0.86)$

Ref

Ref

Receipt of chemotherapy

No

Yes

Unknown

Year of diagnosis

2004-2007

2008-2011

2012-2015

$0.86(0.77-0.95)$

$0.78(0.71-0.85)$

$0.32(0.26-0.39)$

$0.80(0.68-0.93)$

$1.49(1.38-1.60)$

$0.67(0.56-0.80)$

Ref

$1.10(1.02-1.18)$

$\begin{array}{lr}5.1-10 \mathrm{~cm} & \text { Ref } \\ 10.1-15 \mathrm{~cm} & 1.05(0.97-1\end{array}$

$1.45(1.35-1.57)$

.86)

$1.04(0.96-1.12)$

Abbreviations: CCl, Charlson-Deyo comorbidity index; MPNST, malignant peripheral nerve sheath tumor; NOS, not otherwise specified; OR, odds ratio.

$\begin{array}{rrr}.065 & 1.09(0.97-1.22) & .146 \\ .004 & 0.90(0.80-1.00) & .056 \\ <.001 & 0.90(0.82-1.00) & .039 \\ <.001 & 0.70(0.63-0.78) & <.001 \\ .016 & 1.12(0.94-1.35) & .214 \\ <.001 & 0.40(0.32-0.49) & <.001 \\ .004 & 0.91(0.78-1.08) & .286\end{array}$

Ref

$\begin{array}{rrr}.218 & 1.03(0.95-1.12) & .421 \\ <.001 & 0.82(0.75-0.89) & <.001\end{array}$

Ref

$1.39(1.28-1.51) \quad<.001$

Ref

$1.33(1.22-1.45) \quad<.001$

$0.63(0.52-0.76) \quad<.001$

$<.001 \quad 0.63(0.52-0.76) \quad<.001$

Ref

$1.08(1.00-1.17) \quad .060$

$1.17(1.08-1.27)$

$<.001$

\begin{tabular}{rrr}
.355 & $1.08(1.00-1.17)$ & .060 \\
.014 & $1.17(1.08-1.27)$ & $<.001$ \\
\hline
\end{tabular}

Multivariate Analysis

OR $(95 \% \mathrm{Cl}) \quad P$ Value

Ref

$\begin{array}{lll}.374 & 0.97(0.87-1.08) & .588 \\ .076 & 0.97(0.86-1.09) & .614 \\ .046 & 0.94(0.83-1.08) & .401 \\ .228 & 0.81(0.27-2.39) & .697\end{array}$

Ref

$0.86(0.79-0.94) \quad .001$

$0.81(0.68-0.98) \quad .027$

$0.68(0.50-0.92) \quad .013$

$\begin{array}{lll}.001 & 0.68(0.50-0.92) & .013\end{array}$

\section{Ref}

$0.65(0.54-0.78) \quad<.001$

$0.47(0.42-0.53) \quad<.001$

$0.36(0.33-0.39)<.001$

$0.41(0.34-0.50)<.001$ 
eTable 3. Factors Associated With Receipt of Radiotherapy in Patients With Abdominal/Pelvic Tumors

Univariate Analysis

Multivariate Analysis

\begin{tabular}{|c|c|c|c|c|}
\hline \multirow{2}{*}{ Factor } & & & & \\
\hline & OR $(95 \% \mathrm{Cl})$ & $P$ Value & OR $(95 \% \mathrm{Cl})$ & $P$ Value \\
\hline \multicolumn{5}{|l|}{ Age } \\
\hline$<70 y$ & Ref & & Ref & \\
\hline$\geq 70 y$ & $0.87(0.78-0.97)$ & .009 & $0.86(0.75-0.99)$ & .045 \\
\hline \multicolumn{5}{|l|}{ Sex } \\
\hline Male & Ref & & Ref & \\
\hline Female & $0.76(0.69-0.84)$ & $<.001$ & $0.81(0.72-0.89)$ & $<.001$ \\
\hline \multicolumn{5}{|l|}{ Race/Ethnicity } \\
\hline Non-Hispanic White & Ref & & Ref & \\
\hline Non-Hispanic Black & $0.78(0.66-0.92)$ & .004 & $0.79(0.66-0.95)$ & .010 \\
\hline Hispanic & $1.00(0.82-1.22)$ & .994 & $1.01(0.82-1.25)$ & .915 \\
\hline Other & $0.80(0.63-1.01)$ & .065 & $0.81(0.63-1.04)$ & .099 \\
\hline
\end{tabular}

Facility area

Metropolitan Ref

Rural

$1.44(1.00-2.08)$

.743

Unknown

$1.02(0.76-1.38)$

.048

Facility location

East Ref

South

$0.89(0.77-1.03)$

.127

Central

$1.21(1.04-1.40)$

.015

$1.06(0.90-1.25)$

.507

-

West

$1.12(0.93-1.34)$

.234

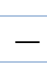

$-$

$-$

45

Unknown

Ref

$\sqrt{2}$

$0.92(0.79-1.07)$

1.27 (1.08-1.48)

.285

$1.13(0.95-1.34)$

.175

$0.98(0.80-1.20)$

.858

Ref

Nonacademic

1.04 (0.94-1.16)

.437

Academic

\section{Ref}

Commercial

$0.86(0.77-0.96)$

Medicare

$1.01(0.82-1.25)$

$0.96(0.73-1.26)$

Medicaid

$0.81(0.60-1.10)$

Uninsured

$0.81(0.60-1.10)$

Ref

$\leq 40$ miles

$0.88(0.78-0.98)$

0.87 (0.53-1.43)

.024

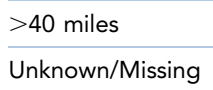

$0.87(0.53-1.43)$

.574

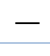

-

Ref

$\begin{array}{lll}.006 & 0.93(0.80-1.07) & .281 \\ .894 & 1.04(0.83-1.30) & .727 \\ .777 & 1.04(0.78-1.39) & .775 \\ .184 & 0.84(0.61-1.15) & .273\end{array}$

Ref

$\geq 21 \%$

$1.07(0.91-1.25)$

$1.07(0.92-1.25)$

$1.13(0.97-1.33)$

$0.82(0.49-1.38)$
$13 \%-20.9 \%$

$7 \%-12.9 \%$

$<7 \%$

Unknown

\begin{tabular}{ll}
.437 \\
.359 \\
.122 \\
.461 & - \\
\hline
\end{tabular}

\section{Ref}

$0.83(0.74-0.94) \quad .003$

$0.81(0.49-1.36) \quad .433$

$\begin{array}{ll}- & - \\ - & - \\ - & - \\ - & - \\ - & -\end{array}$

(continued on next page) 


\begin{tabular}{|c|c|c|c|c|}
\hline Factor & \multicolumn{2}{|c|}{ Univariate Analysis } & \multicolumn{2}{|c|}{ Multivariate Analysis } \\
\hline \multicolumn{5}{|l|}{ Zip code income level, USD } \\
\hline$<\$ 38,000$ & Ref & & - & - \\
\hline$\$ 48,000-\$ 62,999$ & $1.08(0.92-1.27)$ & .328 & - & - \\
\hline$\geq \$ 63,000$ & $1.06(0.91-1.23)$ & .438 & - & - \\
\hline Unknown & $0.75(0.45-1.26)$ & .279 & - & - \\
\hline \multicolumn{5}{|l|}{$\mathrm{CCl}$ score } \\
\hline 0 & Ref & & - & - \\
\hline \multicolumn{5}{|l|}{ Histology } \\
\hline Unclassified & Ref & & Ref & \\
\hline Undifferentiated pleomorphic sarcoma & $1.21(0.99-1.47)$ & .063 & $1.19(0.97-1.46)$ & .096 \\
\hline Fibrosarcoma/Myxofibrosarcoma & $0.84(0.70-1.01)$ & .061 & $0.95(0.78-1.15)$ & .581 \\
\hline Liposarcoma & $0.74(0.64-0.86)$ & $<.001$ & $0.79(0.68-0.93)$ & .003 \\
\hline Leiomyosarcoma & $0.56(0.49-0.64)$ & $<.001$ & $0.59(0.51-0.68)$ & $<.001$ \\
\hline Synovial sarcoma & $1.48(1.09-1.99)$ & .011 & $1.36(0.99-1.87)$ & .055 \\
\hline Angiosarcoma & $0.39(0.27-0.56)$ & $<.001$ & $0.41(0.28-0.59)$ & $<.001$ \\
\hline MPNST & $0.93(0.72-1.19)$ & .557 & $0.93(0.71-1.20)$ & .563 \\
\hline 2 & Ref & & Ref & \\
\hline 3 & $1.50(1.34-1.69)$ & $<.001$ & $1.40(1.24-1.59)$ & $<.001$ \\
\hline \multicolumn{5}{|l|}{ Receipt of chemotherapy } \\
\hline No & Ref & & Ref & \\
\hline Yes & $1.32(1.16-1.50)$ & $<.001$ & $1.17(1.02-1.35)$ & .023 \\
\hline Unknown & $0.68(0.50-0.94)$ & .019 & $0.65(0.47-0.91)$ & .011 \\
\hline \multicolumn{5}{|l|}{ Year of diagnosis } \\
\hline $2004-2007$ & Ref & & Ref & \\
\hline 2008-2011 & $0.99(0.88-1.12)$ & .911 & $1.01(0.89-1.14)$ & .931 \\
\hline 2012-2015 & $0.80(0.71-0.91)$ & $<.001$ & $0.84(0.74-0.96)$ & .010 \\
\hline
\end{tabular}

Abbreviations: $\mathrm{CCl}$, Charlson-Deyo comorbidity index; MPNST, malignant peripheral nerve sheath tumor; OR, odds ratio. 